\title{
High-Affinity Anti-DNA Antibody Parallels Clinical Course of Immunoadsorption Therapy for Systemic Lupus Erythematosus
}

\author{
Masanori Funauchi, Shinya Ikoma, Hiroshi Enomoto, \\ Motoki Ohno, Kohji Kinoshita, Atsushi Horiuchi and Noriyuki Kurata*
}

\begin{abstract}
Anti-DNA antibody, especially high-affinity anti-DNA antibody (ADNA), is thought to have an important role in the pathogenesis of lupus nephritis. In this study, ADNA which binds to doublestranded DNA under a high concentration of sodium chloride was measured in patients who had received immunoadsorption (IA) therapy with a dextran-sulfate column. Titers of high-affinity ADNA in the cases with renal dysfunction tended to be higher than in those without renal dysfunction. The change in the titer of high-affinity ADNA paralleled the clinical course. These findings suggest that measurement of high-affinity ADNA is useful for follow-up of the clinical course of patients who have undergone IA therapy.
\end{abstract}

(Internal Medicine 35: 367-372, 1996)

Key words: lupus nephritis, dextran-sulfate column, sodium chloride

\section{Introduction}

Systemic lupus erythematosus (SLE) is one of the autoimmune diseases characterized by multiple organ disorders caused by immune complexes (IC) which consist of antiDNA antibody (ADNA) (1,2). In particular, the ADNA responsible for the pathogenesis of SLE is believed to have a high affinity for double-stranded DNA (dsDNA) and to be a cationic IgG-subclass antibody $(3,4)$. SLE is currently treated with corticosteroids and immunosuppressive agents to inhibit the production of ADNA, however there is also a potential therapeutic effect in the removal of circulating ADNA and IC by plasmapheresis for drug-resistant cases. There have been several reports including ours describing that such severe cases of SLE have been successfully treated by selective removal of circulating ADNA by adsorption onto a dextran-sulfate column (5-8). In this paper, using the sera during this immunoadsorption (IA) therapy, we investigated whether the measurement of ADNA with high affinity for dsDNA in the serum is useful for follow-up of the patients who have undergone the treatment with this column.

\section{Materials and Methods}

\section{Determination of ADNA}

Conventional ADNA and high affinity antibody to dsDNA were determined using kits named RIA II (DPC, Japan) and HiA (DPC, Japan) respectively, both kits employing a modified Farr method (9). Briefly, a mixture of $25 \mu \mathrm{l}$ of serum and $200 \mu \mathrm{l}$ of ${ }^{125}$ I-labeled dsDNA was incubated in the presence or absence of $125 \mathrm{mM} \mathrm{NaCl}$ in RIA II or $\mathrm{Hi}-\mathrm{A}$ for 2 hours at $37^{\circ} \mathrm{C}$. After precipitation by ammonium sulfate of complexes consisting of ADNA and dsDNA, the ratio of radioactivity of the complexes to the total radioactivity was calculated. The titer $(\mathrm{U} / \mathrm{ml})$ of ADNA in RIA II was determined using a standard curve made by standard sera of $\mathrm{WHO}(10)$, and the ADNA titer in Hi-A, the above ratio (\%), was used as the titer of high affinity antibody to dsDNA according to the manufacturer's instructions.

\section{Patients}

Five patients with severe SLE, who met the criteria of ARA (11), were treated by IA therapy using a dextran-sulfate column. Their sera before and during the IA therapy were stored at $70^{\circ} \mathrm{C}$ until measurement of ADNA. The procedure of IA therapy is reported elsewhere (7). Briefly, plasma was separated from blood using a polysulfone column (FS-05, Nikiso, Japan) and

From the Third Department of Internal Medicine, Kinki University School of Medicine, Osaka and *the First Department of Internal Medicine, Kagawa Medical University School of Medicine, Kagawa

Received for publication October 2, 1995; Accepted for publication March 4, 1996

Reprint requests should be addressed to Dr. Masanori Funauchi, the Third Department of Internal Medicine, Kinki University School of Medicine, 377-2 OhnoHigashi, Osaka-Sayama, Osaka 589 
it was passed through a dextran-sulfate column using an apheresis unit (MA0-01, Yokogawa Corp., Japan). Plasma of $60 \mathrm{ml} / \mathrm{kg}$ was processed during each IA session, which was repeated weekly a total of 4 to 6 times. Five patients, all female from 23 to 43 years of age (mean, 32.8), who were resistant to conventional drug therapies including oral prednisolone and cyclophosphamide which were administered during the preceding period from 2 to 14 years (mean, 6.8). Major symptoms and signs at the beginning of IA therapy were shown by Table 1 . ADNA determined by RIA II in the sera from all patients was greater than $100 \mathrm{U} / \mathrm{ml}$. Table 2 shows the clinical courses of the five cases. During the IA therapy, cases 2, 4, and 5 kept taking the same doses of prednisolone (10-25 mg/day). In order to suppress the rebound phenomenon of ADNA production, $500 \mathrm{mg}$ of methylprednisolone (mPSL) in cases 1 and 3, and $600 \mathrm{mg}$ of cyclophosphamide (CP) in case 2 was administered intravenously after IA session. In case $4,4 \mathrm{mg} / \mathrm{kg}$ of cyclosporin A (CyA) was given everyday after the first IA session. The clinical course of each case was assessed by comparing the disease activity and existence of proteinuria (more than $0.1 \mathrm{~g} /$ day) before and after the IA therapy as following. According to the criteria by Japanese Ministry of Health and Welfare, patients with three or more of the following items are regarded as having active disease; fever (more than $37^{\circ} \mathrm{C}$ ), arthralgia, erythema, oral stomatitis or massive hair loss, leukopenia (less than 4,000/ $\mu \mathrm{l}$ ), hypo-complementemia (less than $20 \mathrm{CH} 50 \mathrm{U}$ ), accelerated erythrocyte sedimentation rate (more than $30 \mathrm{~mm} / \mathrm{h}$ ), LE cell phenomenon, hypoalbuminemia (less than $3.5 \mathrm{~g} / \mathrm{dl}$ ). Cases in whom either 4 or more items disappeared or 3 items as well as proteinuria disappeared were regarded as improved (I), cases in whom 2 items disappeared, as slightly improved (SI), or one or less item disappeared, as no change (NC), and if new items increased it was considered as worsened (W).

\section{Statistical analysis}

Significance of the correlation between two groups was evaluated by F-test.

Table 1. Patient Profile

\begin{tabular}{|c|c|c|c|c|c|c|c|c|c|}
\hline Case & $\begin{array}{l}\text { Age } \\
(\mathrm{yr})\end{array}$ & Sex & $\begin{array}{l}\text { Period } \\
\text { after Dx } \\
\quad(y r)\end{array}$ & $\begin{array}{l}\text { Chief } \\
\text { complaint }\end{array}$ & $\begin{array}{l}\text { WBC } \\
(/ \mu \mathrm{l})\end{array}$ & $\begin{array}{c}\text { CH50 } \\
\text { (U/ml) }\end{array}$ & $\begin{array}{l}\text { Urinary } \\
\text { protein } \\
\text { (g/day) }\end{array}$ & $\begin{array}{c}\text { Cellular } \\
\text { cast }\end{array}$ & $\begin{array}{c}\text { ADNA } \\
\text { by RIA } \\
(\mu / \mathrm{ml})\end{array}$ \\
\hline 1 & 23 & $\mathrm{~F}^{2}$ & 6 & Skin rash & 3,300 & 10.2 & 1.0 & + & 237 \\
\hline 2 & 25 & $\mathrm{~F}$ & 8 & Proteinuria & 4,800 & 14.7 & 2.0 & + & 134 \\
\hline 3 & 34 & $\mathrm{~F}$ & 2 & $\begin{array}{l}\text { Facial rash } \\
\text { Arthralgia }\end{array}$ & 1,900 & 40.8 & 0 & - & 214 \\
\hline 4 & 43 & $\mathrm{~F}$ & 4 & Renal failure & 3,600 & 8.0 & $\mathrm{ND}^{3}$ & ND & 106 \\
\hline 5 & 39 & $\mathrm{~F}$ & 14 & $\begin{array}{l}\text { Facial rash } \\
\text { Psychosis }\end{array}$ & 2,340 & 27.0 & 0 & - & 299 \\
\hline
\end{tabular}

${ }^{1}$ diagnosis, ${ }^{2}$ female, ${ }^{3}$ not done.

Table 2. Clinical Course

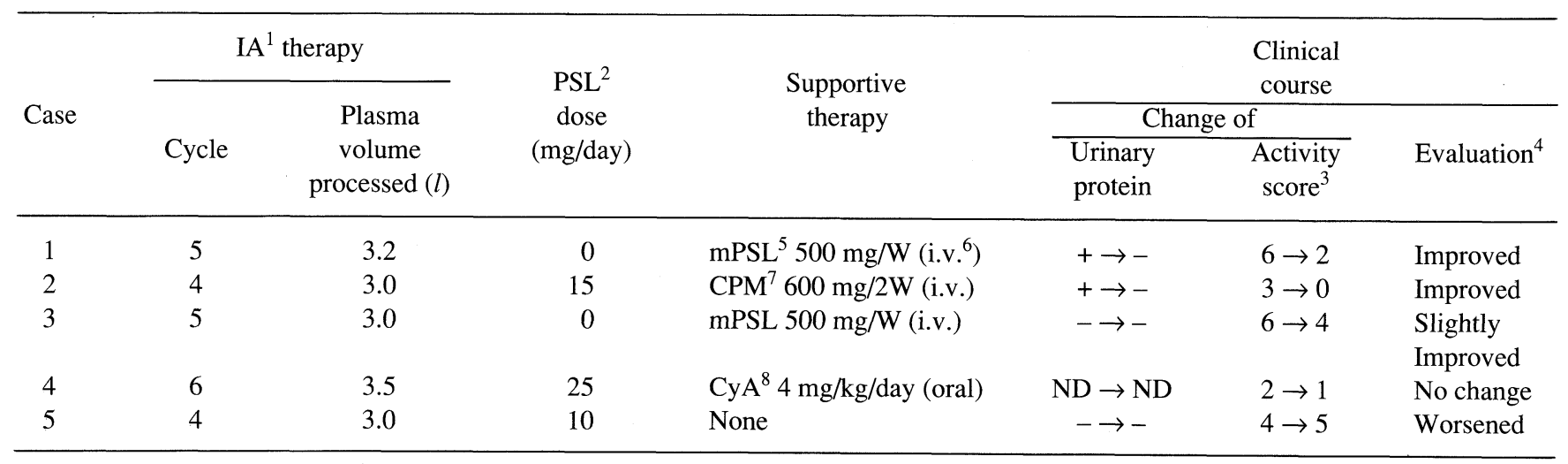

${ }^{1}$ immunoadsorption therapy, ${ }^{2}$ prednisolone, ${ }^{3}$ disease activity score described in "Materials and Methods", ${ }^{4}$ evaluation of clinical course described in "Materials and Methods", ${ }^{5}$ methyl prednisolone, ${ }^{6}$ intravenously, ${ }^{7}$ cyclophosphamide, ${ }^{8}$ cyclosporin A. 


\section{Results}

\section{Clinical courses}

Cases 1 and 2 belonged to I; case 3, SI; case 4, who was complicated by chronic renal failure and was on hemodialysis, NC; case 5, took no supportive therapy (as described in Patients section), W (Table 2).

\section{Relationship between the ADNA titers by RIA and Hi-A}

ADNA was determined by RIA and Hi-A using serum samples drawn on the same day before IA therapy and just before the fourth IA session, and the relationship between the ADNA titers by the two methods are shown in Fig. 1. There was a positive correlation between titers by the two methods $(p<0.05)$. Before IA therapy, all samples showed a high titer of ADNA of over $100 \mathrm{U} / \mathrm{ml}$ by RIA, but there was a wide range of distribution from slightly to markedly elevated at $\mathrm{Hi}-\mathrm{A}$, although the total number of cases was not sufficient for statistical analysis (Fig. 2).

\section{Relationship between renal dysfunction and ADNA by the two methods}

By RIA, ADNA titers of the two cases (cases 3, 5) without renal dysfunction showed a high level of ADNA of over $200 \mathrm{U} /$ $\mathrm{ml}$, and had a tendency to be higher than the titers of those with proteinuria or chronic renal failure, although the difference was not significant. By Hi-A, in the 2 patients without renal dysfunction, one was high (case 5) and the other was low (case 3), while titers of the three cases with proteinuria or chronic renal failure were relatively high (Fig. 3).

\section{Relationship between the titer of ADNA and clinical course}

Serum ADNA titers before IA therapy measured by RIA and $\mathrm{Hi}-\mathrm{A}$ were compared in association with clinical courses. The titer of case 5, who had worsened after IA therapy (W), was markedly high, and that of the case 4 (NC) was moderately high. The other three cases in SI and I showed moderate to high ADNA titers. On the other hand, the titers by Hi-A of the cases in $\mathrm{W}$ and $\mathrm{NC}$ were high, while that of case 3 in SI was slightly over the normal range, and the other 2 cases (cases 1,2) in I showed high titers (Fig. 4).

\section{Change of ADNA titer}

Figure 5 shows the change of ADNA titer by RIA and Hi-A during the IA therapy. By RIA, the titer of case 5 (W) was high at the beginning and also through out the therapy. In cases 1 to 3 (I or SI), initial high titers were decreased during the IA therapy. In case 4 (NC), the titer increased markedly during the IA therapy. On the other hand, by Hi-A, the ADNA titers of the two cases in $\mathrm{W}$ and $\mathrm{NC}$ were high at the beginning and both increased during the therapy. The titers of cases 1 and 2 (I) showed high titers at the beginning and markedly decreased during the therapy, while that of case 3 (SI) was relatively low at the beginning and then normalized after IA therapy.

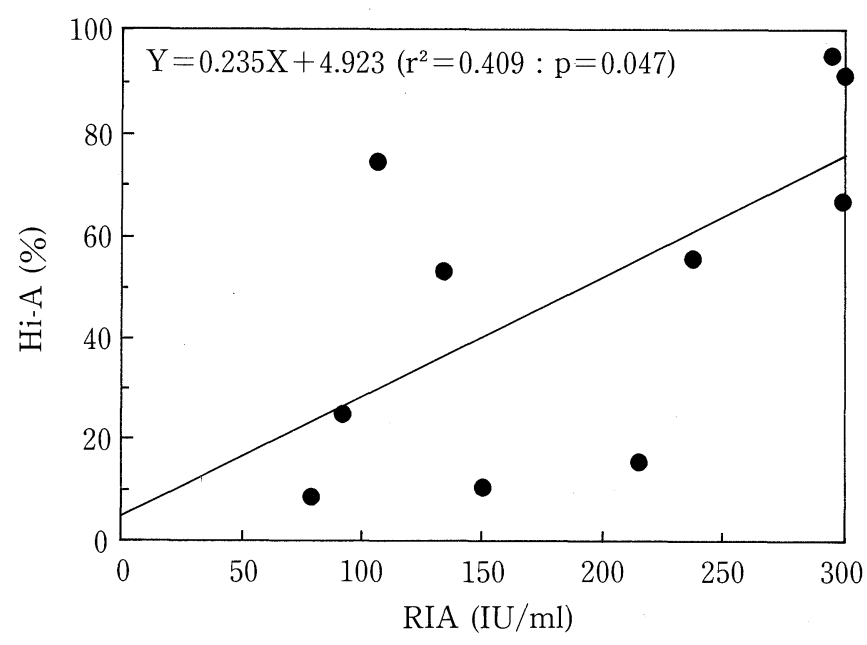

Figure 1. Relationship between the ADNA titers by RIA and $\mathrm{Hi}-\mathrm{A}$ in all samples drawn at the beginning and just before the fourth session of IA therapy.

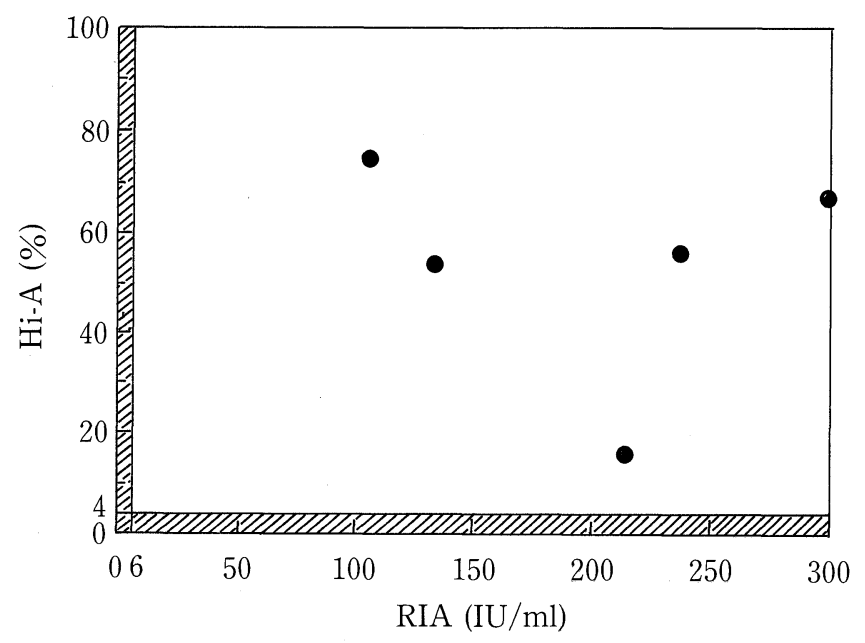

Figure 2. Relationship between the ADNA titers by RIA and $\mathrm{Hi}-\mathrm{A}$ in the samples drawn only at the beginning. Hatched areas represent the cut off level of each method.

\section{Discussion}

Recently we demonstrated that IA therapy is useful for the treatment of patients with lupus nephritis resistant to conventional drugs $(7,8)$. Among the numerous patients with SLE who underwent IA therapy, we studied 5 cases with various clinical courses (improved, 2; slightly improved, 1; not changed, 1; worsened, 1). In case $5(\mathrm{~W})$, the ADNA titer was markedly high by both methods at the beginning, and remained still high just before the fourth session of IA, showing a correlation with the clinical course, while the titer just after each session of IA was decreased (data not shown). This was thought to be due to the fact that this case took no supportive drugs in addition to PSL; 

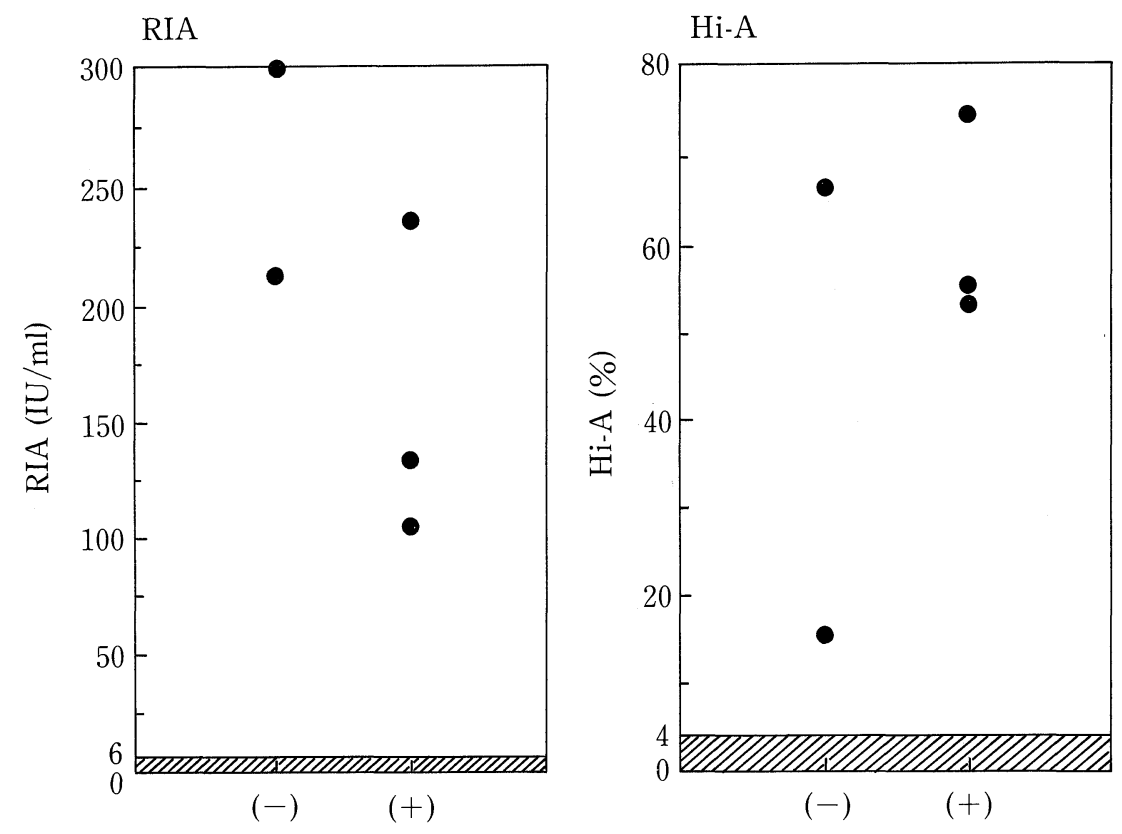

Figure 3. Relationship between renal dysfunction and ADNA by the RIA and Hi-A. (+) cases with, and (-) cases without proteinuria or chronic renal failure. Hatched areas represent the cut off level of each method.
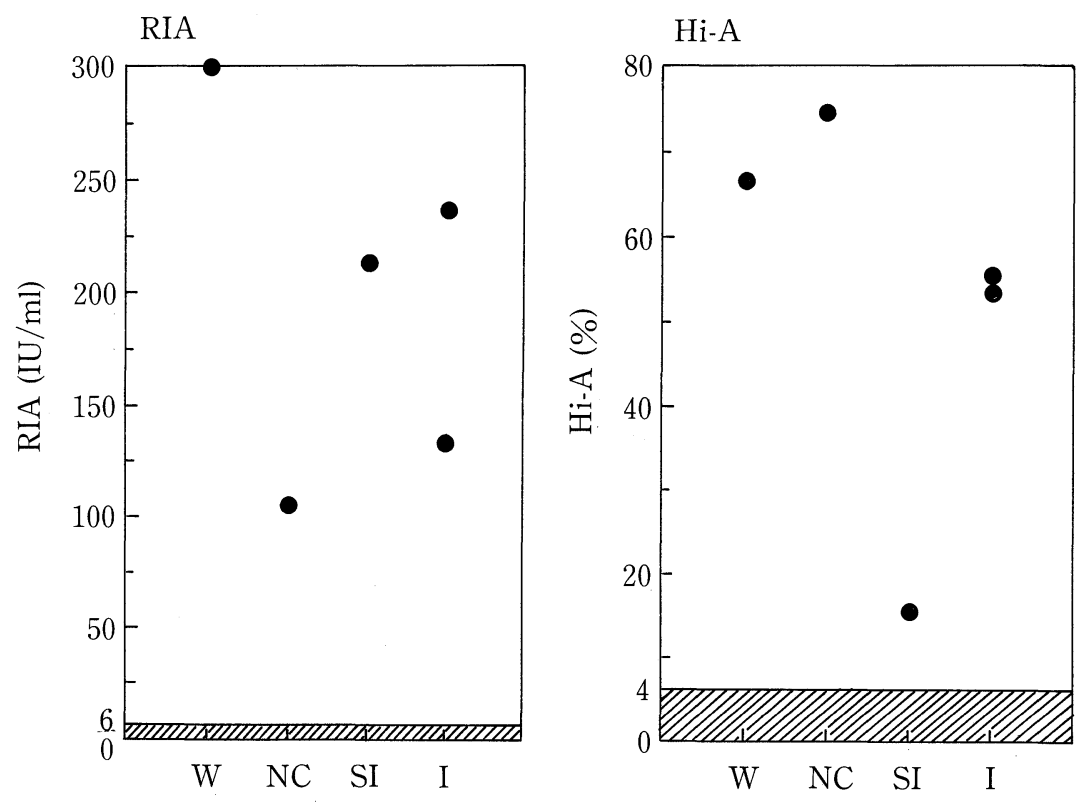

Figure 4. Relationship between the titer of ADNA at the beginning and during the clinical course. Hatched areas represent the cut off level of each method. I: improved, SI: slightly improved, NC: not changed, W: worsened. Details of the changes during the clinical course are described in text.

such is the case with plasmapheresis, in which a rebound phenomenon of immunoglobulin production often occurs.

It has been reported that the Farr assay of ADNA is a method which can detect high affinity antibodies by making low affinity antibodies dissociate from DNA by using ammonium sulfate (12). On the other hand, a high concentration of sodium chloride 

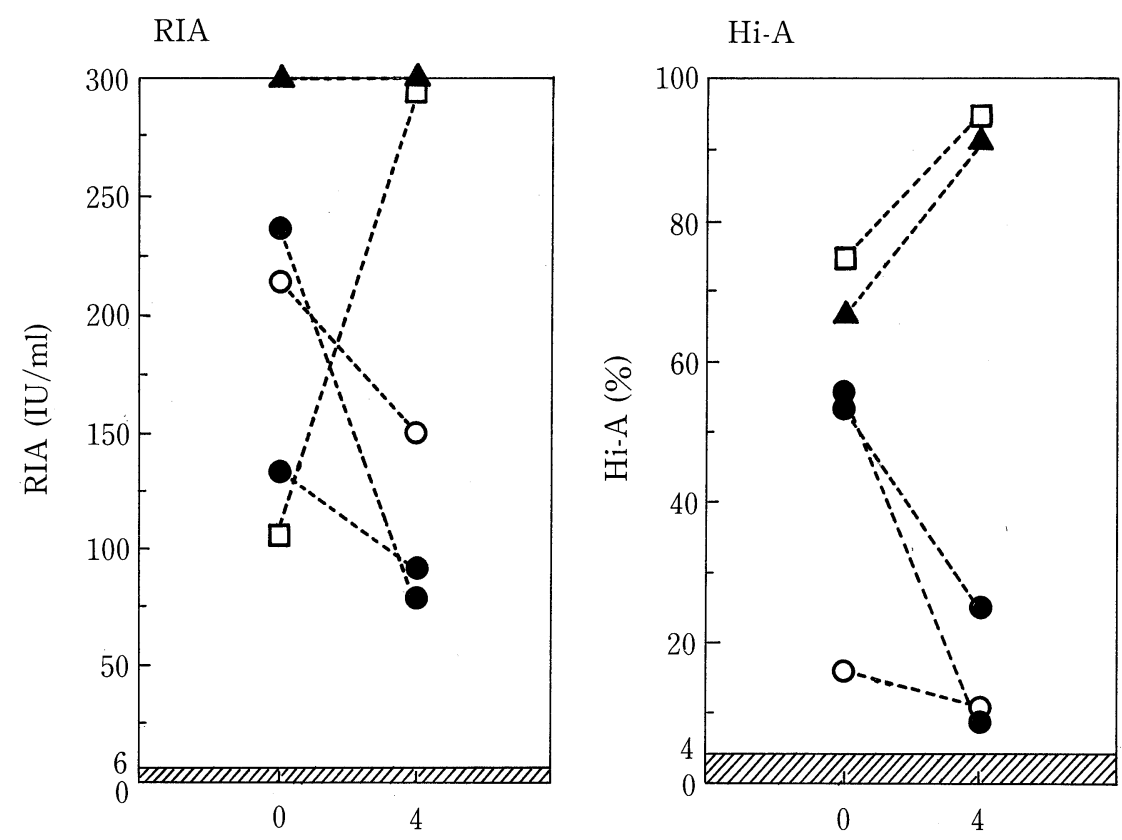

Figure 5. Change of ADNA titer at the beginning and just before the fourth session of IA therapy by the RIA and Hi-A. Triangles represent the worsened cases; open squares: case with no change, closed circles: improved cases, open circles: slightly improved case. 0 , before IA therapy; 4 , just before the fourth IA session.

is thought to make an environment in which ADNA further dissociates from DNA. Therefore, ADNA detected by the HiA kit we used is believed to consist of a large part of highaffinity ADNA (12-14). It has been reported by several investigators $(14,15)$ that this high-affinity ADNA binds to the basement membrane of the glomeruli, and that it is associated with renal dysfunction. In the present study, there was a weakly positive correlation between the ADNA titers by RIA and HiA of all samples before and during the IA therapy. However, it was more likely that titers of the cases with renal dysfunction had a tendency to be higher in Hi-A than in RIA, although this was not statistically significant.

Because various supportive drugs were given in the present cases, it seems difficult to select the patients with an indication of IA therapy only based on the levels of ADNA determined by either method. However, in the cases with high titers of ADNA by Hi-A, those who had a good clinical courses showed a marked decrease of the titers, while those who had a bad clinical course maintained high titers. In addition, among the three cases in which IA therapy was effective, two with markedly elevated titers by Hi-A showed a high score of improvement and one with a slightly elevated titer did not. On the other hand, the level of the titers by RIA before IA therapy obviously did not parallel the clinical course.

These data suggest that ADNA detected in a high concentration of sodium chloride might be more closely associated with the pathogenesis of this disease than that detected by RIA. Further, it was more likely that the change of titers of ADNA measured by Hi-A paralleled the clinical course of IA therapy than that measured by RIA. Therefore, measurement of highaffinity ADNA may be useful for the selection of patients for IA therapy. The correlation between the titer of high-affinity ADNA and the clinical outcome by IA therapy should be studied in more cases.

\section{References}

1) Schur PH, Sandson J. Immunologic factors and clinical activity in systemic lupus erythematosus. N Engl J Med 278: 533, 1968.

2) Bruneau C, Benveniste J. Circulating DNA: anti-DNA complexes in systemic lupus erythematosus. Detection and characterization by ultracentrifugation. J Clin Invest 64: 191, 1979.

3) Gauthier VJ, Mannik M. A small proportion of cationic antibodies in immune complexes is sufficient to mediate their deposition in glomeruli. J Immunol 145: 3348, 1990.

4) Vlahakos DV, Foster MH, Adams S, et al. Anti-DNA antibodies form immune deposit at distinct glomerular and vascular sites. Kidney Int 41: 1690, 1992.

5) Hashimoto $H$, Tsuda $H$, Kanai $Y$, et al. Selective removal of anti-DNA and anticardiolipin antibodies by adsorbent plasmapheresis using dextran sulfate columns in patients with systemic lupus erythematosus. J Rheumatol 18: 545, 1991.

6) Suzuki K, Hara M, Harigai M, et al. Continuous removal of anti-DNA antibody using a new extracorporeal immunoadsorption system, in patients with systemic lupus erythematosus using a new extracorporeal immunoadsorption system. Arthritis Rheum 34: 1546, 1991.

7) Minoda M, Funauchi M, Horiuchi A. Clinical evaluation of selective adsorption therapy for anti-DNA antibody in patients with systemic lupus erythematosus. Jpn J Apheresis 13: 125, 1994.

8) Funauchi M, Ohno M, Minoda M, Horiuchi A. Three cases of systemic lupus erythematosus treated by immunoadsorbent plasma perfusion with a dextransulfate column. Therapeutic Plasmapheresis 10: 214, 1992. 


\section{FUNAUCHI et al}

9) Wold RT, Young FE, Tan EM, Farr, RS. Deoxyribonucleic acid antibody, a method to detect its primary interaction with deoxyribonucleic acid. Science 161: 806, 1968.

10) Feltkamp TEW, Kirkwood TBL, Maini RN, Aarden LA. The first international standard for antibodies to double stranded DNA. Ann Rheum Dis 47: 740, 1988.

11) Tan EM, Cohen AS, Fries JF, et al. The 1982 revised criteria for the classification of systemic lupus erythematosus. Arthritis Rheum 25: 1271, 1982.

12) Smeenk RJT, van Rooijen A, Swaak TJG. Dissociation studies of DNA/
anti-DNA complexes in relation to anti-DNA avidity. J Immunol Methods 109: 27, 1988.

13) Yoshida M, Yoshida H, Muso E, et al. Avidity of anti-DNA antibodies and its clinical significance in patients with SLE. Jpn Arch Int Med 34: 89, 1987.

14) McGrath $\mathrm{H} \mathrm{Jr}$, Biunda JJ Jr. A longitudinal study of high and low avidity antibodies to double-stranded DNA in systemic lupus erythematosus. Arthritis Rheum 28: 425, 1985.

15) Geshwin ME, Steinberg AD. Qualitative characteristics of anti-DNA antibodies in lupus nephritis. Arthritis Rheum 17: 947, 1974. 